\title{
Special feature: Computational and simulation paradigms for evolutionary and institutional economics
}

\author{
Shu-Heng Chen ${ }^{1}$
}

Published online: 20 April 2017

(C) Japan Association for Evolutionary Economics 2017

Keywords Computational paradigm $\cdot$ Simulation paradigm $\cdot$ Computational intelligence $\cdot$ Socialist calculation debate $\cdot$ Tacit knowledge $\cdot$ Evolutionary computation

\section{Motivation and background}

This special issue is planned and published as a post-conference publication of the 21st International Conference on Computing in Economics and Finance (CEF 2015), the largest conference on computational economics for two decades. The long-lasting tradition of publishing special issues after the conference was stopped in the past few years, and some path-breaking excitements became untraced. Without publication, the 'descendants' of CEF simply could not experience the shining past once made by their 'ancestors'.

In 2015, the renowned international publisher Springer worked with Japanese Association for Evolutionary Economics (JAFEE) to publish her well-standing journal, Evolutionary and Institutional Economics Review (EIER) (Aruka 2014; Yagi et al. 2015). Before this collaboration, EIER was operated independently by JAFEE. Maintaining an international journal solely by an academic society is very demanding. Collaborating with an international publisher doubtlessly helps lift EIER to a new plateau and reach a larger web of readers. It also enhances EIER's collaboration with various international societies. The idea of publishing a special issue of CEF 2015 is just a case in point. We are grateful for the kind support of Prof. Kiichiro Yagi (editor in chief) and Prof. Yuji Aruka (coordinating editor) to

Shu-Heng Chen

chen.shuheng@gmail.com

1 AI-ECON Research Center, Department of Economics, National Chengchi University, Taipei, Taiwan 
make this special issue possible. We also benefit very much from the logistic assistance capably provided by the managing editor Yutaka Hirachi.

\section{Computational economics and evolutionary economics}

Publishing a special issue on computational economics in a journal of evolutionary and institutional economics indicates the interdisciplinary nature of each of these sister sciences. Computational economics deals with problems which are complex enough to defy an analytic solution. Deviating from Newtonian Microeconomics, it treats economics as a science of complex systems, which require complexity thinking in terms of both ontology and epistemology.

Evolutionary economics originated from Thomas Malthus (1766-1834), Alfred Marshall (1842-1934), Thorstein Veblen (1857-1929), and Armen Alchian (1914-2013); it clothes economics with a biologically inspiring view. With this view, the static notion of equilibrium and the accompanied equilibrium analysis is pedagogically useful but has limited applicability in practice. For evolutionary economists, economic or social systems are more complex than biological systems (Beckage et al. 2013). Interesting "dynamics" are usually neither describable nor analytically derivable. Instead, they have to be discovered through experiences or simulations, and these dynamics will not converge to any recognizable patterns but constantly changing. ${ }^{1}$ In this sense, computational economics and evolutionary economics can be nicely fitted into the two sides of the same coin. On one side, computational economics can be considered as the methodology for evolutionary economics; on the other side, evolutionary economics can be regarded as the epistemology of economics employing computational (simulation) methodology.

The article "Information Aggregation and Computational Intelligence" (authored by Shu-Heng Chen and Ragupathy Venkatachalam) provides an illustration on how computational economics and evolutionary economics can be non-trivially intertwined. This article addresses a fundamental issue which just gained its momentum these days: Whether machine intelligence can eventually substitute (outperform) human intelligence and will eventually take away men's jobs. Despite its seeming freshness, this issue is not new. Attention to it can be long-dated back to Moreno and Jennings (1934). However, the traditional way to address the issue is to place the competition on a one-on-one basis, i.e., one brain vs. one machine, or one man vs. one robot (Brynjolfsson and McAfee 2014; Davenport and Kirby 2016). Differing from this conventional approach, Chen and Venkatachalam consider the competition in a collective manner, i.e., crowds of brains vs. crowds of machines, or, simply, markets vs. platforms. In this way, the issue is immediately related to the famous socialist calculation debate, in which many great economists were involved, including Friedrich Hayek (1899-1992).

Chen and Venkatachalam's inquiry begins with computational intelligence or, more specifically, evolutionary intelligence, an evolutionary perspective of

\footnotetext{
1 This is what is familiarly known as the Class-IV dynamics or also known as "on the edge of chaos." See Wolfram (2002).
} 
intelligence. With the advent of the digital society, we can imagine a cyber society as a counterpart of the physical world. Basically, what we did, what we said, and even what we thought will have their "copies" in the clouds. There are bio-inspired artificial agents (robots, algorithms), who are traveling into this cyberspace and designed to make good use of this information. The activities carried out by these 'smart agents' will help us solve many decision-making problems, including resources allocation problems currently carried out by the so-called tatonnement process well portrayed in general equilibrium analysis (Fisher 1983), or simply known as markets. If that happens, then markets may be replaced, and socialist calculation become possible. $^{2}$

In their analysis, Chen and Venkatachalam argued that there is a fundamental challenge to this perfect substitution or the road to a frictionless economy. ${ }^{3}$ Basically, leaving the possible mathematics of matching problems aside, which may be handled by computational intelligence, the data in the clouds may not be sufficient enough for machines to learn all tacit knowledge of humans as well as their indescribable or vague perception of the inner or outer world.

\section{Computational economics and institutional economics}

The core element of institutional economics is the institution, regardless of being explicit or hidden, structured or informal. It is a study of her formation or crafting process, which inevitably is an evolutionary process. Therefore, evolutionary and institutional economics sometimes are closely entangled. As stated above, computation, specifically, the bio-inspired computation, is a presentation of the evolutionary process; it can be used to shed light on the crafting process of institutions. However, one has to admit that, up to this point, this potential of computational economics has only been limitedly explored. What currently may draw more attention from computational economists is the design of institutions. The design issue, normally known in the form of the mechanism design or the market design, is a broad subject covering mathematical economics (Narahari 2014), behavioral economics (Thaler and Sunstein 2008), and experimental economics (Smith 1991). However, what can severely challenge these disciplines is the complexity issue, as well put by Ostrom (2005).

If the individuals who are crafting and modifying rules do not understand how particular combinations of rules affect actions and outcomes in a particular

\footnotetext{
${ }^{2}$ Consider the following case. A college student upon his/her graduation, his/her resume is automatically generated, and then automatically sent to a matching pool where vacancies are matched with talents, followed by the provision of the most favorable deal for both sides. A sequence of information processing, preference discovering, and skill endorsing, job matching, wage bargaining problems is automatically handled by artificial agents in the cyberspace (Chen et al. 2016). When this happens, the labor market as we understand in the conventional sphere is gone. Hence, in this case, a collection of computing agents takes over the labor market usually run by humans.

3 This frictionless economy, coined by Chen et al. (2016), can also be related to the 'good life' economy as well portrayed by John Maynard Keynes (1883-1946) and his protégé Ernst Friedrich Schumacher (1911-1977). See Chick (2013).
} 
ecological and cultural environment, rule changes may produce unexpected, and at times, disastrous outcomes. (Ibid, p.3)

From Wolfram's elementary cellular automata, almost the first lesson taken in agent-based computation economics (Chen 2015), one is convinced that a tiny change in the behavioral rule can have a dramatic macroscopic impact. The reason is that the system to which the rule applies may be irreducible, which indicates that those micro-causalities are largely unpredictable and can only be known through simulations (experiments). This latter property causes computational economics to play a very supportive role for the study of mechanism design or institutional economics. The usefulness of the computational and experimental approach has already been well recognized by leading economists.

Game theory, the part of economics that studies the "rules of the game," provides a framework with which to address design. But design involves a responsibility for detail; this creates a need to deal with complications. Dealing with complications requires not only careful attention to the institutional details of a particular market, it also requires new tools, to supplement the traditional analytical toolbox of the theorist. The first thesis of this paper is that, in the service of design, experimental and computational economics are natural complements to game theory. (Roth 2002, p. 1342)

The article "Transitional student admission mechanism from tracking to mixing: An agent-based policy analysis", authored by Connie H Wang, Bin-Tzong Chie and Shu-Heng Chen, gives us a concrete demonstration of how agent-based computational paradigm can be applied to studying the design of school admission mechanism. This article compares the matching performance of four different types of matching mechanisms, namely the Serial Dictatorship, the Boston Mechanism, the Chinese Parallel, and the Taipei Mechanism. The former two are well-known in the literature. The latter two are the variants of the former two; they each vary from the former two in a sophisticated manner, which causes the consequences of the designs less analytical. Simulation paradigm (agent-based simulation) becomes the only viable tool to gain understanding in this situation. Specifically, for many policy designs, just knowing the mean effect is not sufficient; sometimes, the distribution effect, i.e., how the policy can affect different stakeholders differently becomes an inescapable issue. The distribution effect involves some fine details of agents' heterogeneity. This part is generally assumed away by the mainstream economic models due to its analytical tractability. The article shows that agent-based model can be a solution for this demanding task; it further shows that evaluation of different mechanisms can be partial and even misleading if the distribution effect is entirely ignored.

The article "The decomposition and policy meaning of China's carbon emission intensity," (authored by Jinhe Jiang) addresses the measurement problem for policy design. It calculates the per capita carbon emissions of primary energy (CEPE) and final carbon emission intensity (FCEI), i.e., final carbon emission per unit of GDP. It further introduces a new decomposition method for carbon emission and its temporal and structural change based on China's statistics during the past 20 years. 
This decomposition may allow us to understand and evaluate the impact of economic and energy policies on carbon emissions. The article per se serves as a good introduction to the change, structure and some characteristics of energy consumption and carbon emissions in China.

Acknowledgements The guest editor is grateful for the research support in the form of Ministry of Science and Technology (MOST) Grants, MOST 103-2410-H-004-009-MY3. We are also grateful to the following reviewers for their painstaking efforts made to this special issue: Peter Anselmo, Alexandrova Kabadjova Biliana, Kiyoshi Izumi, Elina Khachatryan, William Lawless, Cassey Lee, Dietmar Maringer, Sameer Rege, Lin Xue, and Ryuichi Yamamoto.

\section{References}

Aruka Y (2014) Our move to a new Springer Series from the present form of EIER: a retrospective on the past decade. Evolut Inst Econ Rev 11(2):91-93

Beckage B, Kauffman S, Gross L, Zia A, Koliba C (2013) More complex complexity: Exploring the nature of computational irreducibility across physical, biological, and human social systems. In: Zenil $\mathrm{H}$ (ed.), Irreducibility and computational equivalence: 10 years after Wolfram's a new kind of science. Springer, Springer Berlin Heidelberg, pp. 79-88

Brynjolfsson E, McAfee A (2014) The second machine age: work, progress, and prosperity in a time of brilliant technologies. WW Norton \& Company

Chen SH (2015) Agent-based computational economics: how the idea originated and where it is going. Routledge

Chen S-H, Chie B-T, Tai C-C (2016) Smart societies. In: Roger F, Chen S-H, Dopher K, Heukelom F, Mousavi S (eds.), Routledge Handbook of Behavioral Economics, Routledge. Chapter 18, pp. $250-285$

Chen S-H, Venkatachalam R (2016) Information aggregation and computational intelligence: limits to price discovery. Evolut Inst Econ Rev. doi:10.1007/s40844-016-0048-z

Chick V (2013) Economics and the good life: Keynes and Schumacher. Econ Thought 2(2):33-45

Davenport T, Kirby J (2016) Only humans need apply: winners and losers in the age of smart machines. HarperCollins Publishers, New York

Fisher F (1983) Disequilibrium foundations of equilibrium economics. Cambridge University Press, Cambridge

Jiang J (2016) The decomposition and policy meaning of China's carbon emission intensity. Evolut Inst Econ Rev. doi:10.1007/s40844-016-0062-1

Moreno J, Jennings H (1934) Who shall survive? Nervous and Mental Disease Publishing Company, Washington, DC

Narahari Y (2014) Game theory and mechanism design. World Scientific, Singapore

Ostrom E (2005) Understanding institutional diversity. Princeton University Press, Princeton

Roth A (2002) The economist as engineer: game theory, experimentation, and computation as tools for design economics. Econometrica 70(4):1341-1378

Smith V (1991b) Papers in experimental economics, Cambridge University Press, cambridge

Thaler R, Sunstein C (2008) Nudge: improving decisions about health, wealth, and happiness. Penguin Books, New York

Wang CH, Chie B-T, Chen S-H (2016) Transitional student admission mechanism from tracking to mixing: an agent-based policy analysis. Evolut Inst Econ Rev. doi:10.1007/s40844-016-0058-x

Wolfram S (2002) A new kind of science, Wolfram Media, Champaign

Yagi K, Aruka Y, Fujimoto T (2015) A new stage of the evolutionary and institutional economics review. Evol Inst Econ Rev 12(1):1-2 